\title{
Factors associated with delay in diagnosis among tuberculosis patients in the north of Iran
}

Mahmood Moosazadeh, ${ }^{1,2}$ Motahareh Kheradmand, ${ }^{2}$ Mohsen Aarabi, ${ }^{3}$ Mahdi Afshari, ${ }^{4}$ Mohammadreza Parsaee, ${ }^{5}$ Asghar Nezammahalleh, ${ }^{5}$ Amirhossein Hessami ${ }^{6}$

Check for updates

pISSN: 0853-1773 • elSSN: 2252-8083 https://doi.org/10.13181/mji.oa.204476 Med J Indones. 2021;30:60-5

Received: January 06, 2020

Accepted: November 06, 2020

Authors' affiliations:

${ }^{1}$ Gastrointestinal Cancer Research Center, Non-communicable Diseases Institute, Mazandaran University of Medical Sciences, Sari, Iran, ${ }^{2}$ Health Sciences Research Center, Addiction Institute, Mazandaran University of Medical Science, Sari, Iran, ${ }^{3}$ Department of Family Medicine, School of Medicine, Mazandaran University of Medical Sciences, Sari, Iran, ${ }^{4}$ Department of Community Medicine, School of Medicine, Zabol University of Medical Sciences, Zabol, Iran, ${ }^{5}$ Mazandaran University of Medical Sciences, Sari, Iran, ${ }^{6}$ Student Research Committee, School of Medicine, Mazandaran University of Medical Sciences, Sari, Iran

\section{Corresponding author:}

Amirhossein Hessami

Student Research Committee, School of Medicine, Mazandaran University of Medical Sciences (Vice-Chancellor for Research), Moallem Square, Sari, Mazandaran, Iran

Tel/Fax: +98-11-33257230/

+98-11-33261244

E-mail: hessami.amirhossein@gmail.com

\begin{abstract}
BACKGROUND Recognizing factors that affect delay in diagnosis in patients with pulmonary tuberculosis (TB) is critical. This study aimed to identify such factors among TB patients in the north of Iran.
\end{abstract}

METHODS In this retrospective cohort study, we reviewed patient's medical records from the TB registration system of the Health Deputy of Mazandaran University of Medical Sciences, Sari, Iran that was responsible for the TB registry in the province from 2007 to 2017. All hospitals affiliated with the university, including private hospitals, reported TB cases directly to the health deputy. Patient's gender, age, TB smear result, TB type, imprisonment, diabetes, nationality, residence area, and drug use were considered factors of delay in diagnosis, which was defined as a delay of $>30$ days between symptom onset and diagnosis. Data from 3,453 patients were analyzed using the chi-square test and logistic regression models.

RESULTS The frequency of patients with delay in diagnosis was $67.7 \%$. There was no association between delay in diagnosis and gender $(p=0.194)$, TB type $(p=0.140)$, and diabetes $(p=0.198)$. On the other hand, old age ( $\geq 60$ years) was related to delay in diagnosis $(\mathrm{OR}=1.37 ; 95 \% \mathrm{Cl}=1.12-1.68 ; p=0.002)$. The chance of delay in diagnosis in prisoners was lower than in non-prisoners $(\mathrm{OR}=0.62 ; 95 \% \mathrm{Cl}=0.46-0.82 ; p=0.001)$.

CONCLUSIONS Old age was a risk factor for delay in diagnosis, and interestingly, prisoners had been diagnosed significantly faster.

KEYWORDS delayed diagnosis, Iran, tuberculosis
Tuberculosis (TB) is the ninth leading cause of death worldwide. ${ }^{1}$ In 2012, the prevalence of smearpositive pulmonary TB among the general population of Mazandaran province (north of Iran) was 4.3 in 100,000.2 According to previous evidence, factors involved in diagnostic delay include living in rural

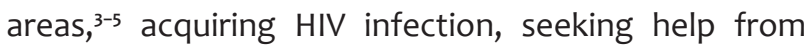
multiple healthcare providers, and receiving initial care from primary healthcare facilities and informal care providers. However, poorly recalling the exact time of symptom onset and ignoring factors related to delay were some study limitations. ${ }^{3}$

Identifying factors related to delay in diagnosis of patients with pulmonary TB could play a critical role in TB prevention within the community by shortening treatment delay. It can lead to a significant reduction in the economic and social burden of pulmonary TB patients. ${ }^{3-5}$ Considering the aforementioned factors 
and insufficient research data in Iran, especially in Mazandaran province, this study aimed to determine the factors associated with delay in diagnosis among patients with TB in the north of Iran.

\section{METHODS}

In this retrospective cohort study, we reviewed patient's medical records in the TB registry system of the Health Deputy of Mazandaran University of Medical Sciences from 2007 to 2017. This area is located in the north of Iran at Caspian Sea Coast with a population of 2.6 million. The province includes the cities of Sari, Galugah, Behshahr, Neka, Miandoroud, Juybar, Ghaemshahr, Savadkuh, Amol, Mahmoud Abad, Fereydoon-Kenar, Babolsar, Nour, Nowshahr, Chalous, Tonekabon, Ramsar, Abasabad, Simorgh, and Kelardasht. Patients aged $>15$ years were directly asked about the onset of main TB symptoms, including cough lasting >3 weeks, coughing up blood, fever, and night sweats at the beginning of treatment (after final disease diagnosis was made by smear testing). After physicians made the diagnosis, health deputy staff registered TB patients in the TB registration system (available at http://tb-lep.behdasht.gov.ir). All data regarding the patients' disease, including demographic data, symptom onset date, diagnosis date, other clinical data, and prescribed medications, had been entered into the registry system.

Data were collected in Excel format using TB registration software (including all factors) and transferred to SPSS version 21 (IBM Corp., USA). The difference between symptom onset and diagnosis was calculated to determine the delay in diagnosis. Delay in diagnosis was defined based on a cut-off reported by Storla et $\mathrm{al}^{6}$ and Getnet et $\mathrm{al}^{7}$ of $\geq 30$ days. Smear results were classified to $3+(>10$ bacilli in each microscopic field), 2+ (1-10 bacilli in each microscopic field), 1+ (10-99 bacilli in 100 microscopic fields), scanty (1-9 bacilli in 100 microscopic fields), and negative based on smear density. Chi-square test was used to compare some factors including gender, age group, TB type, diabetes, imprisonment, nationality, drug use, and residence area between patients with delay in diagnosis. HIV infection was excluded from our analysis because of the limited number of cases. A logistic regression model was used to adjust the effect of confounding variables in predicting the effect of all factors in the delay because the number of variables was limited. Smear results and delay in diagnosis were analyzed using logistic regression. A $p$-value of $<0.05$ was considered statistically significant. This study was approved by the Research Ethics Committee of Mazandaran University of Medical Sciences (code: IR.MAZUMS.REC.1397.038).

\section{RESULTS}

Data of all patients have been extracted from the TB registration software. Of 3,453 patients investigated during the study period, the frequency of male subjects was 2,171 (62.9\%). The prevalence of patients with delay in diagnosis was $67.7 \%$. The mean and median delay in TB diagnosis were 126.6 (standard deviation $=74.4$ ) and 38 days, respectively. The prevalence of delay in diagnosis in men was slightly higher than in women. In addition, it was also higher in the 30-44 year age group than in the 15-29 year age group. Delay in the diagnosis of prisoner patients was significantly lower than that of nonprisoners (Table 1).

Using multivariate regression, the chance of delay in diagnosis was significantly higher in the 60 and 3044 year age groups than in the 15-29 year age group (odds ratio $[O R]=1.37, p=0.002$ and $O R=1.44, p<0.001$, respectively). The odds of delay in diagnosis in prisoner was significantly lower than that in non-prisoner (OR = $0.62, p=0.001$; Table 1 ).

The prevalence of delay in diagnosis among patients with $3+, 2+, 1+$, scanty, and negative sputum smear results were $73.0 \%, 71.8 \%, 66.6 \%, 67.2 \%$, and $63.2 \%$, respectively. Table 2 presents the OR for delay in diagnosis based on smear results.

\section{DISCUSSION}

Delay in TB diagnosis is a major issue affecting the transmission, mortality, and severity of the disease. ${ }^{6,8}$ A meta-analysis by Getnet et $\mathrm{al}^{7}$ reported a $42 \%$ delay in diagnosis of >30 days in pulmonary TB patients in low- and middle-income countries, including Iran. We found that more than half of the TB patients in the study area had a delay in diagnosis of >30 days. Loutet et al ${ }^{9}$ studied a delay in TB diagnosis in England, which is a high-income country, and found that $34 \%$ of TB cases had delay in diagnosis of $>4$ months. Although their definition of delay was longer than in the study by Getnet et al, ${ }^{7}$ the prevalence of delay in diagnosis 
Table 1. Factors related with delay in diagnosis among TB patients

\begin{tabular}{|c|c|c|c|c|c|c|c|}
\hline \multirow{3}{*}{ Variables } & \multirow{3}{*}{ Total number } & \multicolumn{3}{|c|}{ Univariate analysis } & \multicolumn{3}{|c|}{ Multivariate analysis } \\
\hline & & \multicolumn{2}{|c|}{ Delay in diagnosis, $\mathrm{n}(\%)$} & \multirow{2}{*}{$p$} & \multirow{2}{*}{ OR } & \multirow{2}{*}{$95 \% \mathrm{Cl}$} & \multirow{2}{*}{$p$} \\
\hline & & $<30$ days & $\geq 30$ days & & & & \\
\hline Gender & & & & 0.139 & & & \\
\hline Male & 2,171 & $682(31.4)$ & $1,489(68.6)$ & & 1.00 & & \\
\hline Female & 1,282 & $434(33.9)$ & $848(66.1)$ & & 0.90 & $0.77-1.05$ & 0.194 \\
\hline Age group (years) & & & & 0.001 & & & \\
\hline $15-29$ & 781 & $296(37.9)$ & $485(62.1)$ & & 1.00 & & \\
\hline $30-44$ & 1,001 & $300(30.0)$ & 701 (70.0) & & 1.44 & $1.18-1.76$ & $<0.001$ \\
\hline $45-49$ & 643 & $211(32.8)$ & $432(67.2)$ & & 1.23 & $0.98-1.54$ & 0.071 \\
\hline$\geq 60$ & 1,028 & $309(30.1)$ & 719 (69.9) & & 1.37 & $1.12-1.68$ & 0.002 \\
\hline TB type & & & & 0.075 & & & \\
\hline Extrapulmonary & 911 & $316(34.7)$ & $595(65.3)$ & & 1.00 & & \\
\hline Pulmonary & 2,542 & $800(31.5)$ & $1,742(68.5)$ & & 1.13 & $0.96-1.33$ & 0.140 \\
\hline Diabetes & & & & 0.198 & & & \\
\hline No & 3,166 & $1,033(32.6)$ & $2,133(67.4)$ & & 1.00 & & \\
\hline Yes & 287 & $83(28.9)$ & $204(71.1)$ & & 1.11 & $0.84-1.45$ & 0.457 \\
\hline Prisoner & & & & 0.003 & & & \\
\hline No & 3,217 & 1,019 (31.7) & $2,198(68.3)$ & & 1.00 & & \\
\hline Yes & 236 & 97 (41.1) & 139 (58.9) & & 0.62 & $0.46-0.82$ & 0.001 \\
\hline Drug user & & & & 0.086 & & & \\
\hline No & 3,365 & $1,095(32.5)$ & $2,270(67.5)$ & & 1.00 & & \\
\hline Yes & 88 & 21 (23.9) & 67 (76.1) & & 1.48 & $0.89-2.46$ & 0.126 \\
\hline Nationality & & & & 0.274 & & & \\
\hline Non-Iranian & 89 & $24(27.0)$ & $65(73.0)$ & & 1.00 & & \\
\hline Iranian & 3,364 & $1,092(32.5)$ & $2,272(67.5)$ & & 0.73 & $0.45-1.18$ & 0.201 \\
\hline Residency area & & & & 0.542 & & & \\
\hline Rural & 1,393 & 442 (31.7) & $951(68.3)$ & & 1.00 & & \\
\hline Urban & 2,060 & $674(32.7)$ & $1,386(67.3)$ & & 0.98 & $0.84-1.14$ & 0.788 \\
\hline
\end{tabular}

$\mathrm{Cl}=$ confidence interval; $\mathrm{OR}=$ odds ratio; $\mathrm{TB}=$ tuberculosis

Table 2. Delay in diagnosis in patients with pulmonary TB based on smear results

\begin{tabular}{|c|c|c|c|c|c|}
\hline \multirow{2}{*}{ Smear results } & \multicolumn{2}{|c|}{ Delay (days), n (\%) } & \multicolumn{3}{|c|}{ Univariate regression } \\
\hline & $<30$ & $\geq 30$ & OR & $95 \% \mathrm{Cl}$ & $p$ \\
\hline Negative & $247(36.8)$ & $425(63.2)$ & 1.00 & 1.00 & \\
\hline Scanty & $21(32.8)$ & $43(67.2)$ & 1.19 & $0.69-2.05$ & 0.531 \\
\hline $1+$ & $204(33.4)$ & $406(66.6)$ & 1.15 & $0.91-1.45$ & 0.215 \\
\hline $2+$ & $118(28.2)$ & $300(71.8)$ & 1.47 & $1.13-1.92$ & 0.004 \\
\hline $3+$ & $210(27.0)$ & $568(73.0)$ & 1.57 & $1.25-1.96$ & $<0.001$ \\
\hline
\end{tabular}

$\mathrm{Cl}=$ confidence interval; $\mathrm{OR}=$ odds ratio; $\mathrm{TB}=$ tuberculosis

was lower in England than in low- or middle-income countries. Alavi et $\mathrm{al}^{10}$ and Alipour et $\mathrm{a}^{11}$ estimated the prevalence of delay in diagnosis in Iran at $65.5 \%$ and $60.4 \%$, respectively.
Many factors are involved in delay of TB diagnosis in different countries, including personal and health system-related ones. ${ }^{12-15}$ Said et al ${ }^{16}$ reported a median diagnostic delay of 3 weeks, and only $5 \%$ of patients 
had delay of $>4$ weeks. The findings of this study showed that there was no significant association between delay in diagnosis and gender, TB type, residency area, diabetes, addiction, and nationality. Moreover, old age was a risk factor for delay in diagnosis, whereas prisoners experienced lower delay in diagnosis than non-prisoners. In our study, although the number of male patients with delay were slightly higher than that of female patients, the difference was insignificant. However, Buregyeya et $\mathrm{al}^{17}$ reported a significant association between male gender and diagnosis delay. Johansson et al ${ }^{18}$ reported that the main factor contributing to the delay in diagnosis among men was the fear of diagnosis and treatment expenses, and men also seek care and neglect symptoms until diseases reach advanced stages. A study in Iran by Alavi et $\mathrm{al}^{10}$ demonstrated that delay in diagnosis was significantly higher in women. The meta-analysis results showed that in several studies, women experienced delay more than men, whereas some other studies showed converse results, ${ }^{6}$ which were similar to our findings. Cultural and social factors related to independence, transportation difficulty, lack of education, and financial issues may contribute to the higher rates of delay in diagnosis among women in developing countries. ${ }^{33,19}$

Old age is a risk factor for delay in diagnosis among TB patients. ${ }^{6,7}$ Das et $\mathrm{al}^{20}$ reported that age $>27.5$ years was the factor associated with a delay of $>30$ days in TB patients. In a study by Said et al, ${ }^{16}$ the OR of delay in diagnosis was only $6 \%$ higher in the $25-$ 45 year age group than in the 18-24 year age group, which showed that this factor was not associated with diagnostic delay. ${ }^{16}$ However, the OR in this study was $44 \%$ higher in 30-44 year age group than in 15-29 year age group. This could explain the higher TB infection risk in children. ${ }^{21}$

Prisoners have a higher risk of getting infected by TB since they are a marginalized population. ${ }^{21}$ Babamahmoodi et $\mathrm{a}^{22}$ reported that a delay in diagnosis was significantly higher among prisoners and suggested that weakness in diagnosis and referral system was the reason for the delay. Similarly, Nasehi et $\mathrm{a}^{15}$ concluded that non-prisoners are at risk of delay in TB diagnosis. Conversely, our study found a negative association between delay in diagnosis and being a prisoner, and delay in diagnosis was more prevalent in non-prisoners. This issue could be a positive sign of early TB diagnosis in prisoners in Iran. ${ }^{15}$
Diabetes mellitus increases the risk of $\mathrm{TB}^{23}$ as patients with diabetes have 1.55 - to 3.59 -fold increased risk of TB infection. ${ }^{24}$ Diabetes can also affect treatment outcomes and delayed clearance of TB patients. ${ }^{25}$ In a study by Chen et al, ${ }^{26}$ the prevalence of delay in diagnosis for $>30$ days in TB patients with diabetes was significantly higher than in patients without diabetes. Diabetes could add to the burden of this disease that can cause delay for seeking care. ${ }^{27}$ In our study, delay was higher in patients with diabetes; however, it was not statistically significant. Similarly, Alavi et al ${ }^{10}$ found no significant association between diabetes and TB diagnosis delay. This can be an indication of good diabetes care and screening in Mazandaran, which might prevent its negative effects on TB diagnosis.

Living in rural areas is an essential factor affecting delays in diagnosis in many countries. ${ }^{6,14}$ Although Das et $\mathrm{a}^{20}$ concluded that rural residency was significantly associated with patient and health system delay, our study found otherwise. Similar studies conducted in the north of $\operatorname{Iran}^{22}$ and Tunisia ${ }^{13}$ also reported no significant difference in delay between urban and rural populations. However, the study by Nasehi et $\mathrm{al}^{15}$ in Iran found that the diagnostic delay was significantly longer in urban areas than in rural areas. This situation could be because medical care availability and diagnosis in rural areas are similar to urban areas, and rural residents can receive sufficient medical care, ${ }^{22}$ and the family physician system can decrease TB delay in rural areas, ${ }^{15}$ which is being done in Mazandaran province.

We found that $30.61 \%$ of patients were diagnosed with advanced bacteriologic grade $\left(3^{+}\right)$pulmonary TB. Some studies have suggested that TB diagnostic delay is associated with smear positivity, ${ }^{26}$ whereas Storla et $\mathrm{al}^{6}$ concluded that diagnostic delay is associated with negative sputum smear. The smear positivity results in our study were comparable with that in Nasehi's study, which indicated the following results: $3.4 \%$ were scanty, $36 \% 1+, 23.2 \% 2+$, and $37.4 \%$ $3+.{ }^{15}$

Drug abuse could be a contributing factor of TB infection by affecting the environment and risk behaviors of users, ${ }^{28}$ and it has been associated with a delay in diagnosis in these patients. ${ }^{29}$ Patients with drug abuse were delayed in seeking care and had limited access to routine health care, leading to the spread of TB. ${ }^{30}$ 
Immigration history or illegal residency has been identified as a risk factor of delay in diagnosis. ${ }^{6}$ Afghan immigrants and Iraqi and Pakistani travelers could exacerbate the TB condition in Iran. ${ }^{15}$ Several factors contribute to the delay in diagnosis and treatment in immigrants including economic, cultural, legislative, social, and health systems.31 However, in our study, there was no significant association between nationality and diagnosis delay.

The current study has several limitations for consideration. During the data registry, patients were directly asked about the onset time of symptoms, which could be affected by recall bias. This study only evaluated total delay in diagnosis, whereas patient and health system delays were not evaluated separately. Socioeconomic factors could also affect delay in diagnosis, although it needs further investigation.

In conclusion, this study showed that the frequency of patients with delay ( $>30$ days) in diagnosis was $67.7 \%$. Old age was also a risk factor for delay in diagnosis. In addition, prisoners had been diagnosed significantly faster than non-prisoners.

\section{Conflict of Interest}

The authors affirm no conflict of interest in this study.

\section{Acknowledgment}

We would like to acknowledge the Student Research Committee of Mazandaran University of Medical Sciences for supporting this project.

\section{Funding Sources}

This work was supported by the Student Research Committee of Mazandaran University of Medical Sciences (grant number 183).

\section{REFERENCES}

1. World Health Organization. Global tuberculosis report 2017. Geneva: World Health Organization; 2017.

2. Nasehi MM, Moosazadeh M, Amiresmaeili MR, Parsaee MR, Nezammahalleh A. The epidemiology of factors associated with screening and treatment outcomes of patients with smear positive pulmonary tuberculosis: a population-based study. J Mazandaran Univ Med Sci. 2012;21(1):9-18.

3. Bogale S, Diro E, Shiferaw AM, Yenit MK. Factors associated with the length of delay with tuberculosis diagnosis and treatment among adult tuberculosis patients attending at public health facilities in Gondar town, Northwest, Ethiopia. BMC Infect Dis. 2017;17:145.

4. Lin Y, Enarson DA, Chiang CY, Rusen ID, Qiu LX, Kan XH, et al. Patient delay in the diagnosis and treatment of tuberculosis in China: findings of case detection projects. Public Health Action. 2015;5(1):65-9.

5. Mekonnen YA, Abebe L, Fentahun N, Belay SA, Kassa AW. Delay for first consultation and associated factors among tuberculosis patients in Bahir Dar town administration, North West Ethiopia. Am J Health Res. 2014;2(4):140-5.

6. Storla DG, Yimer S, Bjune GA. A systematic review of delay in the diagnosis and treatment of tuberculosis. BMC Public Health.
2008;8:15.

7. Getnet F, Demissie M, Assefa N, Mengistie B, Worku A. Delay in diagnosis of pulmonary tuberculosis in low-and middle-income settings: systematic review and meta-analysis. BMC Pulm Med. 2017;17:202.

8. Sreeramareddy CT, Panduru KV, Menten J, Van den Ende J. Time delays in diagnosis of pulmonary tuberculosis: a systematic review of literature. BMC Infect Dis. 2009;9:91.

9. Loutet MG, Sinclair C, Whitehead N, Cosgrove C, Lalor MK, Thomas HL. Delay from symptom onset to treatment start among tuberculosis patients in England, 2012-2015. Epidemiol Infect. 2018;146(12):1511-8.

10. Alavi SM, Bakhtiyariniya P, Albagi A. Factors associated with delay in diagnosis and treatment of pulmonary tuberculosis. Jundishapur J Microbiol. 2015;8(3):e19238.

11. Alipour N, Sheikhi M, Yazdani Charati J, Mohsenipouya H, Shabankhani B, Rezaii MS. Total delay and associated factors in pulmonary tuberculosis patients in Golestan province. Caspian J Intern Med. 2020;11(1):67-74.

12. Ali U, Zubair UB, Ambreen A, Yousaf H, Kaleem F, Khalil KF. Delay in diagnosis of pulmonary tuberculosis: study of factors related to patients and health care system. J Microbiol Infect Dis. 2017;7(3):119-24.

13. Ben Amar J, Hassairi M, Ben Salah N, Charfi R, Tritar F, Fourati R, et al. Pulmonary tuberculosis: diagnostic delay in Tunisia. Med Mal Infecti. 2016;46(2):79-86.

14. Li Y, Ehiri J, Tang S, Li D, Bian Y, Lin H, et al. Factors associated with patient, and diagnostic delays in Chinese TB patients: a systematic review and meta-analysis. BMC Med. 2013;11:156.

15. Nasehi M, Hassanzadeh J, Rezaianzadeh A, Zeigami B, Tabatabaee H, Ghaderi E. Diagnosis delay in smear positive tuberculosis patients. J Res Med Sci. 2012;17(11):1001-4.

16. Said K, Hella J, Mhalu G, Chiryankubi M, Masika E, Maroa T, et al. Diagnostic delay and associated factors among patients with pulmonary tuberculosis in Dar es Salaam, Tanzania. Infect Dis Poverty. 2017;6:64.

17. Buregyeya E, Criel B, Nuwaha F, Colebunders R. Delays in diagnosis and treatment of pulmonary tuberculosis in Wakiso and Mukono districts, Uganda. BMC Public Health. 2014;14:586.

18. Johansson E, Long NH, Diwan VK, Winkvist A. Gender and tuberculosis control: perspectives on health seeking behaviour among men and women in Vietnam. Health Policy. 2000;52(1):33-51.

19. Shu W, Chen W, Zhu S, Hou Y, Mei J, Bai L, et al. Factors causing delay of access to tuberculosis diagnosis among new, active tuberculosis patients: a prospective cohort study. Asia Pac J Public Health. 2014;26(1):33-41.

20. Das S, Basu M, Mandal A, Roy N, Chatterjee S, Dasgupta A. Prevalence and determinants of delay in diagnosis of pulmonary tuberculosis in Darjeeling district of West Bengal. J Family Med Prim Care. 2017;6(3):627-35.

21. Narasimhan P, Wood J, Maclntyre CR, Mathai D. Risk factors for tuberculosis. Pulmonary medicine. 2013;2013:828939.

22. Babamahmoodi F, Alikhani A, Yazdani Charati J, Ghovvati A, Ahangarkani F, Delavarian L, et al. Clinical epidemiology and paraclinical findings in tuberculosis patients in north of Iran. Biomed Res Int. 2015;2015:381572.

23. Jeon CY, Murray MB. Diabetes mellitus increases the risk of active tuberculosis: a systematic review of 13 observational studies. PLoS Med. 2008;5(7):e152.

24. Al-Rifai RH, Pearson F, Critchley JA, Abu-Raddad LJ. Association between diabetes mellitus and active tuberculosis: a systematic review and meta-analysis. PLoS One. 2017;12(11):e0187967.

25. Lee EH, Lee JM, Kang YA, Leem AY, Kim EY, Jung JY, et al. Prevalence and impact of diabetes mellitus among patients with active pulmonary tuberculosis in South Korea. Lung. 2017;195(2):209-15.

26. Chen HG, Liu M, Jiang SW, Gu FH, Huang SP, Gao TJ, et al. Impact 
of diabetes on diagnostic delay for pulmonary tuberculosis in Beijing. Int J Tuberc Lung Dis. 2014;18(3):267-71.

27. Htun YM, Khaing TM, Yin Y, Myint Z, Aung ST, Hlaing TM, et al. Delay in diagnosis and treatment among adult multidrug resistant tuberculosis patients in Yangon Regional Tuberculosis Center, Myanmar: a cross-sectional study. BMC Health Serv Res. 2018;18(1):878

28. Deiss RG, Rodwell TC, Garfein RS. Tuberculosis and illicit drug use: review and update. Clin Infect Dis. 2009;48(1):72-82.

29. Deponti GN, Silva DR, Coelho AC, Muller AM, Dalcin Pde T. Delayed diagnosis and associated factors among new pulmonary tuberculosis patients diagnosed at the emergency department of a tertiary care hospital in Porto Alegre, South Brazil: a prospective patient recruitment study. BMC Infect Dis. 2013;13:538.

30. Oeltmann JE, Kammerer JS, Pevzner ES, Moonan PK. Tuberculosis and substance abuse in the United States, 19972006. Arch Intern Med. 2009;169(2):189-97.

31. Abarca Tomás B, Pell C, Bueno Cavanillas A, Guillén Solvas J, Pool R, Roura M. Tuberculosis in migrant populations. A systematic review of the qualitative literature. PLoS One. 2013;8(12):e82440. 